\title{
First-principles investigation of phase stability, elastic and thermodynamic properties in $\mathrm{L1}_{2} \mathrm{Co}_{3}(\mathrm{Al}, \mathrm{Mo}, \mathrm{Nb})$ phase
}

\author{
Qiang Yao ${ }^{\text {a,b,*, }}$, Shun-Li Shang ${ }^{\text {b }}$, Yong-Jie Hu ${ }^{\text {b }}$, Yi Wang ${ }^{\text {b }}$, Yan Wang ${ }^{\text {a }}$, Yu-Hong Zhu ${ }^{\text {a }}$, Zi- \\ Kui Liu ${ }^{b}$ \\ a National Supervising \& Testing Center for Engineering Composite Materials' Quality, Jiangsu Provincial \\ Supervising \& Testing Research Institute for Products' Quality, Nanjing 210007, PR China \\ b Department of Materials Science and Engineering, The Pennsylvania State University, University Park, \\ Pennsylvania 16802, United States
}

${ }^{*}$ Corresponding author. E-mail address: yaoqiangjszj@163.com (Q. Yao). 
Abstract: First-principles calculations have been performed to investigate the phase stability, elastic, and thermodynamic properties of $\mathrm{Co}_{3}(\mathrm{Al}, \mathrm{Mo}, \mathrm{Nb})$ with the $\mathrm{L}_{2}$ structure. Calculated elastic constants show that $\mathrm{Co}_{3}(\mathrm{Al}, \mathrm{Mo}, \mathrm{Nb})$ is mechanically stable and possesses intrinsic ductility. It is found that the shear and Young's moduli of $\mathrm{Co}_{3}(\mathrm{Al}, \mathrm{Mo}, \mathrm{Nb})$ are smaller than those of $\mathrm{Co}_{3}(\mathrm{Al}, \mathrm{W})$. Calculated density of states indicate the existence of covalent-like bonding in $\mathrm{Co}_{3}(\mathrm{Al}, \mathrm{Mo}, \mathrm{Nb})$. Temperature-dependent thermodynamic properties of $\mathrm{Co}_{3}(\mathrm{Al}, \mathrm{Mo}, \mathrm{Nb})$ can be described satisfactorily using the Debye-Grüneisen approach, including entropy, enthalpy, heat capacity and linear thermal expansion coefficient, showing their significant temperature dependences. Furthermore the obtained data can be employed in the modeling of thermodynamic and mechanical properties of Co-based alloys to enable the design of high temperature alloys.

Keywords: A. Intermetallics; B. Phase stability; B. Elastic properties; B. Electronic structure; B. Thermodynamic properties; E. ab-initio calculations 


\section{Introduction}

Ni-based superalloys strengthened by $\gamma^{\prime}$ precipitates in $\mathrm{L}_{2}$ structure have been widely used as the high-temperature materials for industrial gas turbines, aircraft engines, and reactors $[1,2]$. However, these superalloys cannot satisfy the increasing demand for materials with highertemperature capabilities. It is found that Co-based alloys display superior hot corrosion resistance at high temperatures compared to Ni-based alloys [2]. Nevertheless, the traditional Cobased alloys exhibit a lower strength at high temperatures with respect to Ni-based alloys, where Ni-based alloys are strengthened by the precipitation hardening effect caused by the formation of $\gamma^{\prime} \mathrm{Ni}_{3}(\mathrm{Al}, \mathrm{Ta})$ phase [3]. However, the $\gamma^{\prime}$ phase has not been applied in Co-based commercial alloys. Interest in Co-based alloys has been fueled because of the discovery of the $\mathrm{L}_{2}$ ordered $\mathrm{Co}_{3}(\mathrm{Al}, \mathrm{W})$ precipitate [4]. The Co-Al-W-base alloys with $\gamma+\gamma^{\prime}$ structures exhibit higher strength at elevated temperatures compared to Ni-based superalloys $[4,5]$. In addition, $\mathrm{Co}_{3}(\mathrm{Ge}, \mathrm{W})$ and $\mathrm{Co}_{3}(\mathrm{Ga}, \mathrm{W})$ precipitates in the $\mathrm{L}_{2}$ structure have also been found in Co-Ge-W and Co-Ga-W ternary systems $[6,7]$. These alloys show higher density compared with the Ni-based superalloys. Very recently, Makineni et al. [8,9] found a new $\mathrm{L1}_{2}$ ordered $\gamma^{\prime}$ precipitate of $\mathrm{Co}_{3}(\mathrm{Al}, \mathrm{Mo}, \mathrm{Nb})$ with a composition of Co-10.6 at.\% Al-8.7 at.\% Mo-4.8 at.\% Nb in the Co-Al-Mo-Nb tungstenfree quaternary alloys. The density of this alloy is comparable to those of Ni-based superalloys. In addition, the tungsten-free alloy has higher specific proof stress compared to the Co- 9 at.\% Al-9.8 at.\% W alloy.

In the past decade, first-principles approach has become an efficient tool for studying phase stability, mechanical, and thermodynamic properties of crystalline materials [10-12]. For example, these properties in $\mathrm{L}_{2} \gamma^{\prime}-\mathrm{Co}_{3}(\mathrm{M}, \mathrm{W})(\mathrm{M}=\mathrm{Al}, \mathrm{Ge}, \mathrm{Ga})$ have been investigated using both first-principles calculations and experiments [13-20], indicating that these $\gamma^{\prime}$ precipitates are 
ductile and have a strengthening effect on the Co matrix. First-principles calculations also show that Ta plays a crucial role in stabilizing $\gamma^{\prime}$ phase for Co-Al-Mo alloys [21]. Although the $\gamma^{\prime}$ precipitates play an important role in the mechanical properties of the $\gamma / \gamma^{\prime}$ two-phase alloys [22], few studies have been reported for the $\gamma^{\prime}-\mathrm{Co}_{3}(\mathrm{Al}, \mathrm{Mo}, \mathrm{Nb})$ precipitate. In the present work, we perform a first-principles study on the phase stability, elastic and thermodynamic properties of the $\mathrm{L}_{2} \mathrm{Co}_{3}(\mathrm{Al}, \mathrm{Mo}, \mathrm{Nb})$ precipitate.

\section{Theoretical methods}

\subsection{Crystal structure}

In the unit cell of $\mathrm{A}_{3} \mathrm{~B}$ compound with the cubic $\mathrm{L1}_{2}$ structure, $\mathrm{A}$ atoms located at face centers and B atoms at cube corners. In our calculations, the chemical formula is assumed as $\mathrm{Co}_{24} \mathrm{Al}_{3} \mathrm{Mo}_{3} \mathrm{Nb}_{2}$ and the nominal composition for the $\mathrm{Co}_{3}(\mathrm{Al}, \mathrm{Mo}, \mathrm{Nb})$ supercell is Co-9.375 at.\% Al- 9.375 at.\% Mo- 6.25 at.\% Nb. All the seventeen possible $2 \times 2 \times 2$ supercell structures are generated for $\mathrm{Co}_{24} \mathrm{Al}_{3} \mathrm{Mo}_{3} \mathrm{Nb}_{2}$ using the Alloy Theoretic Automated Toolkit (ATAT) software [23]. Fig. 1 illustrates the total energies for all the seventeen supercell structures of $\mathrm{L}_{2}$ $\mathrm{Co}_{3}(\mathrm{Al}, \mathrm{Mo}, \mathrm{Nb})$. The structures with the lowest energy (str_1) and the intermediate energy (str_2) are chosen for further investigations of $\mathrm{Co}_{3}(\mathrm{Al}, \mathrm{Mo}, \mathrm{Nb})$, see Fig .1. Note that the str_2 with the intermediate energy can represent a special quasi-random structure (SQS) of $\mathrm{Co}_{3}(\mathrm{Al}, \mathrm{Mo}, \mathrm{Nb})$ to some extent $[24,25]$ (More details are provided in supplementary data). In addition, a $\mathrm{L}_{2} \mathrm{SQS}$ structure constructed by Jiang [18] is also adopted for the $\mathrm{Co}_{3}(\mathrm{Al}, \mathrm{W})$ compound.

\subsection{Computational details}

First-principles calculations on total energies, elastic constants and electronic structures of the $\mathrm{L}_{2} \mathrm{Co}_{3}(\mathrm{Al}, \mathrm{Mo}, \mathrm{Nb})$ precipitate are performed using the projector augmented wave (PAW) 
method as implemented in the Vienna ab initio simulation package (VASP) [26, 27]. Exchange and correlation effects are treated within the density functional theory, using the generalized gradient approximation proposed by Perdew, Burke and Enzerhof (GGA-PBE) [28]. A $8 \times 8 \times 8 k$ point mesh are used. The cutoff energy of plane wave is set as $500 \mathrm{eV}$. Convergence is judged when the energy difference between each step of the electronic iterations is less than $4 \times 10^{-6}$ eV/atom. The electronic density of states (DOS) is obtained using a modified tetrahedron method [29]. The effect of spin polarization has been considered in the present work.

\subsection{Elastic properties}

Elastic constants are calculated using an efficient stress-strain method. The methodology involves applying a set of strains $\left(e=e_{1}, e_{2}, e_{3}, e_{4}, e_{5}\right.$ and $\left.e_{6}\right)$ on a crystal. Here, $e_{1}, e_{2}$, and $e_{3}$ refer to normal strains, and $e_{4}, e_{5}$, and $e_{6}$ to shear strains. The corresponding stresses $\left(\sigma=\sigma_{1}, \sigma_{2}\right.$, $\sigma_{3}, \sigma_{4}, \sigma_{5}$ and $\sigma_{6}$ ) for the deformed crystal are obtained from first-principles calculations. According to the Hooke's law, elastic stiffness constants are then calculated from the $n$ set of strains and the corresponding stresses. More details are described in [30].

The quasistatic approach is used to compute the isothermal elastic constants as a function of temperature. This approach is based on the fact that the temperature dependence of elastic constants is caused mainly by the volume change of crystal at finite temperatures. The methodology can be summarized in three steps as follow: (a) calculating the elastic constants at 0 $\mathrm{K}$ as a function of volume; (b) predicting the volume change as a function of temperature; (c) then computing the temperature dependence of isothermal elastic constants. More details are described in [31]. Generally, the measured elastic constants at high temperatures using the resonance method are isentropic, because the system is adiabatic due to the elastic waves 
traveling faster than the rate of heat conduction. For cubic crystals, the thermodynamic relations can be simplified as [10]

$$
\frac{C_{11}^{S}}{C_{11}^{T}}=\frac{C_{12}^{S}}{C_{12}^{T}}=\frac{C_{P}}{C_{V}} \quad \text { and } \quad C_{44}^{S}=C_{44}^{T},
$$

where $C_{\mathrm{v}}$ and $C_{\mathrm{p}}$ are heat capacities at constant volume and pressure, respectively. $C_{i j}^{S}$ and $C_{i j}^{T}$ represent the isentropic and the isothermal elastic constants, respectively. The Voigt-Reuss-Hill approach is used to calculate the bulk $(B)$, shear $(G)$ and Young's $(E)$ moduli for polycrystalline crystals [32]. Elastic anisotropy parameter is given by

$$
A=\frac{2 C_{44}}{C_{11}-C_{12}}
$$

Young's moduli along some orientations in single crystals are given by [33]

$$
\begin{gathered}
E_{100}=\frac{\left(C_{11}-C_{12}\right)\left(C_{11}+2 C_{12}\right)}{C_{11}+C_{12}} \\
E_{110}=\left\{\frac{C_{11}+C_{12}}{\left(C_{11}+2 C_{12}\right)\left(C_{11}-C_{12}\right)}+\frac{1}{4}\left(\frac{1}{C_{44}}-\frac{2}{C_{11}-C_{12}}\right)\right\}^{-1} \\
E_{111}=\left\{\frac{C_{11}+C_{12}}{\left(C_{11}+2 C_{12}\right)\left(C_{11}-C_{12}\right)}+\frac{1}{3}\left(\frac{1}{C_{44}}-\frac{2}{C_{11}-C_{12}}\right)\right\}^{-1}
\end{gathered}
$$

\subsection{Thermodynamic properties}

Helmholtz free energy $F(V, T)$ in a solid at volume $V$ and temperature $T$ can be approximated by [10],

$$
F(V, T)=E_{0}(V)+F_{v i b}(V, T)+F_{e l}(V, T)
$$


where $E_{0}(V)$ is the static energy at $0 \mathrm{~K}$ without the zero point vibrational energy, $F_{\mathrm{vib}}(V, T)$ the vibrational free energy, and $F_{\mathrm{el}}(V, T)$ the thermal electronic free energy. $F_{\mathrm{vib}}(V, T)$ can be estimated by the empirical Debye-Grüneisen model [34],

$$
F_{v i b}(V, T)=\frac{9}{8} k_{B} \Theta_{D}+k_{B} T\left\{3 \ln \left[1-\exp \left(-\frac{\Theta_{D}}{T}\right)\right]-D\left(\frac{\Theta_{D}}{T}\right)\right\}
$$

where $k_{\mathrm{B}}$ is Boltzmann's constant, $\Theta_{\mathrm{D}}$ the volume-dependent Debye temperature, and $D(x)$ is the Debye function given by

$$
D(x)=\frac{3}{x^{3}} \int_{0}^{x} \frac{z^{3} d z}{e^{z}-1}
$$

The volume-dependent Debye temperature $\Theta_{\mathrm{D}}$ is written as

$$
\Theta_{D}=s A V_{0}^{1 / 6}\left(\frac{B_{0}}{M}\right)^{1 / 2}\left(\frac{V_{0}}{V}\right)^{\gamma}
$$

where $s$ is a scaling factor, $A$ a constant $\left(6 \pi^{2}\right)^{1 / 3} \hbar / k_{B}, V_{0}$ the ground state volume, $M$ the atomic mass, and $B_{0}$ the bulk modulus. The Grüneisen constant $\gamma$ is defined by

$$
\gamma=\frac{1}{2}\left(1+B_{0}^{\prime}\right)-x
$$

with $x=2 / 3$ for high temperature case and $x=1$ for low temperature case. In the present work, the high temperature value is used.

Thermal electronic contribution to Helmholtz free energy is determined by Mermin statistics $F_{e l}(V, T)=E_{e l}(V, T)-T S_{e l}(V, T)$, where $E_{e l}$ is the internal energy and $S_{e l}$ the bare electronic entropy [35].

\section{Results and discussion}




\subsection{Structural properties}

Calculations of total energies as a function of cell volume are carried out to estimate the lattice constants of $\mathrm{Co}_{3}(\mathrm{Al}, \mathrm{Mo}, \mathrm{Nb})$ and $\mathrm{Co}_{3}(\mathrm{Al}, \mathrm{W})$ in the $\mathrm{L}_{2}$ structure. The equilibrium lattice constant is deduced from a 4-parameter Birch-Murnaghan equation of state fitting [35]. The enthalpy of formation $(\Delta \mathrm{H})$ is defined as the enthalpy change of the compound with respect to its constituents in their standard element reference states (SER). Calculated equilibrium lattice constants and values of $\Delta \mathrm{H}$ at $0 \mathrm{~K}$ are summarized in Table 1 , together with other predictions for the $\mathrm{Co}_{3}(\mathrm{Al}, \mathrm{W})$ phase [36]. It can be seen from Table 1 that the calculated lattice constant of $\mathrm{Co}_{3}(\mathrm{Al}, \mathrm{W})$ is $0.3567 \mathrm{~nm}$, which agrees well with the experimental value of $0.3599 \mathrm{~nm}$ [4]. The $\Delta \mathrm{H}$ value is calculated to be $-12.16 \mathrm{~kJ} / \mathrm{mol}$-atom for $\mathrm{Co}_{3}(\mathrm{Al}, \mathrm{W})$, agreeing reasonably well with other theoretical result $(-14.96 \mathrm{~kJ} / \mathrm{mol}$-atom) [36]. Calculated equilibrium lattice constant of $\mathrm{Co}_{3}(\mathrm{Al}, \mathrm{Mo}, \mathrm{Nb})$ is $0.3599 \mathrm{~nm}$, which is slightly larger than that of $\mathrm{Co}_{3}(\mathrm{Al}, \mathrm{W})$.

\subsection{Electronic structures}

The electronic density of states (DOS) for $\mathrm{L}_{2} \mathrm{Co}_{3}(\mathrm{Al}, \mathrm{Mo}, \mathrm{Nb})$ is further calculated, which provides information on the physical basis for the phase stability of the $\mathrm{L1}_{2} \mathrm{Co}_{3}(\mathrm{Al}, \mathrm{Mo}, \mathrm{Nb})$ compound. Fig. 2 shows the total and partial electronic density of states of the $\mathrm{Ll}_{2}$ $\mathrm{Co}_{3}(\mathrm{Al}, \mathrm{Mo}, \mathrm{Nb})$ with the str_1 structure. It is seen that the calculated DOS of $\mathrm{Co}_{3}(\mathrm{Al}, \mathrm{Mo}, \mathrm{Nb})$ presents a well-defined low-energy bonding and high-energy antibonding region. A deep valley near the Fermi level called a pseudo-gap, which separates the bonding states from the antibonding states. This pseudo-gap is mainly due to the d-d hybridization among the transition metal atoms and indicates the existence of covalent-like bonding in $\mathrm{Co}_{3}(\mathrm{Al}, \mathrm{Mo}, \mathrm{Nb})$. Obviously, the phase stability of intermetallic compounds depends on the location of Fermi level [37]. The 
system will be stable if the Fermi level falls in the bonding states. From Fig. 2, we see that the Fermi level is located in the bonding region of the electronic DOS, which makes the $\mathrm{L1}_{2}$ $\mathrm{Co}_{3}(\mathrm{Al}, \mathrm{Mo}, \mathrm{Nb})$ phase stable. The total spin up and spin down electronic DOS of $\mathrm{Co}_{3}(\mathrm{Al}, \mathrm{Mo}, \mathrm{Nb})$ are asymmetric, indicating that they are in ferromagnetic state. In addition, the non-zero densities around the Fermi levels occur for $\mathrm{Co}_{3}(\mathrm{Al}, \mathrm{Mo}, \mathrm{Nb})$, implying the thermal electronic contribution to free energy should be considered, especially at high temperatures.

\subsection{Elastic properties}

Calculated elastic properties of $\mathrm{Co}_{3}(\mathrm{Al}, \mathrm{Mo}, \mathrm{Nb}), \mathrm{Ni}_{3} \mathrm{Al}$, and $\mathrm{Co}_{3}(\mathrm{Al}, \mathrm{W})$ at $0 \mathrm{~K}$ are presented in Table 2, together with other predictions for $\mathrm{Co}_{3}(\mathrm{Al}, \mathrm{W})$ [38]. Experimental elastic properties of $\mathrm{Ni}_{3} \mathrm{Al}$ [39], $\mathrm{Co}_{3}(\mathrm{Al}, \mathrm{W})$ [19] and $\mathrm{Ni}_{3}(\mathrm{Al}, \mathrm{Ta})$ [19] are also listed for comparison. For cubic crystals, lattice stability requires the elastic stiffness constants that satisfy the following conditions [40]:

$$
C_{44}>0, C_{11}+2 C_{12}>0, C_{11}-\left|C_{12}\right|>0
$$

It can be seen from Table 2 that the $\mathrm{L}_{2} \mathrm{Co}_{3}(\mathrm{Al}, \mathrm{Mo}, \mathrm{Nb})$ is elastically stable based on Eq. (11). A good agreement is observed between calculations and measurements, in particular for $\mathrm{Ni}_{3} \mathrm{Al}$ [39]. The elastic constants of $\mathrm{Co}_{3}(\mathrm{Al}, \mathrm{Mo}, \mathrm{Nb})$ with different structures are almost identical, see results for str_1 and str_2. All the shear and Young's moduli of $\mathrm{Co}_{3}(\mathrm{Al}, \mathrm{Mo}, \mathrm{Nb})$ are larger than those of $\mathrm{Ni}_{3} \mathrm{Al}$ and $\mathrm{Ni}_{3}(\mathrm{Al}, \mathrm{Ta})$, but smaller than those of $\mathrm{Co}_{3}(\mathrm{Al}, \mathrm{W})$. Calculated elastic anisotropy parameter $A$ of $\mathrm{Co}_{3}(\mathrm{Al}, \mathrm{Mo}, \mathrm{Nb})$ is smaller than those of $\mathrm{Ni}_{3} \mathrm{Al}$ and $\mathrm{Co}_{3}(\mathrm{Al}, \mathrm{W})$. It was reported that the ductile/brittle behaviors of materials are related to the $B / G$ ratio [41]. If $B / G$ $<1.75$, the material behaves in a brittle manner, otherwise the material in a ductile manner. On the other hand, Pettifor [42] proposed that the bonding character, which reflecting the ductile/brittle behaviors of materials, could be described by the Cauchy pressure $C_{12}-C_{44}$. For metallic bonding, the Cauchy pressure is positive. However, the Cauchy pressure is negative for 
the directional bonding. It can be seen that the $B / G$ ratio is higher than 1.75 and the Cauchy pressure is positive for $\mathrm{Co}_{3}(\mathrm{Al}, \mathrm{Mo}, \mathrm{Nb})$. Therefore, $\mathrm{Co}_{3}(\mathrm{Al}, \mathrm{Mo}, \mathrm{Nb})$ is ductile in nature, and the ductility of $\mathrm{Co}_{3}(\mathrm{Al}, \mathrm{Mo}, \mathrm{Nb})$ is higher than that of $\mathrm{Co}_{3}(\mathrm{Al}, \mathrm{W})$.

The values of $\mathrm{E}_{110} / \mathrm{E}_{100}$ and $\mathrm{E}_{111} / \mathrm{E}_{100}$ are also given in Table 2. Here $\mathrm{E}_{\mathrm{hkl}}$ denotes Young's modulus along the crystal direction of [hkl]. The values of Young's modulus are the largest in the $\langle 111\rangle$ direction and are the smallest in the $\langle 100\rangle$ direction for $\mathrm{Co}_{3}(\mathrm{Al}, \mathrm{Mo}, \mathrm{Nb}), \mathrm{Ni}_{3} \mathrm{Al}$, $\mathrm{Co}_{3}(\mathrm{Al}, \mathrm{W})$ and $\mathrm{Ni}_{3}(\mathrm{Al}, \mathrm{Ta})$. The $\mathrm{E}_{111}$ value is larger than $\mathrm{E}_{100}$ value by $200 \mathrm{GPa}$ for $\mathrm{Co}_{3}(\mathrm{Al}, \mathrm{Mo}, \mathrm{Nb})$. This implies a strong orientation dependence for Young's modulus.

Fig. 3 shows the calculated isothermal elastic constants $C_{i j}^{T}$ and isentropic elastic constants $C_{i j}^{S}$ at different temperatures for the $\mathrm{Ni}_{3} \mathrm{Al}$ phase. An agreement could be found for $C_{12}^{S}$ and $C_{44}^{S}$ between experiments [43] and the present calculations. For $C_{11}^{S}$, the calculated decreasing rate with increasing temperature is slightly smaller than the corresponding experimental measurements. The discrepancy found in the $C_{11}^{S}$ could be attributed to the neglecting of the contributions of $F_{\text {vib }}$ and $F_{\text {el }}$ to these second derivatives [31]. Fig. 4 shows the calculated isentropic elastic constant $C_{i j}^{S}$, elastic properties $(B, G$ and $E)$, Young's modulus in the [hkl] direction $E_{\mathrm{hkl}}, E_{110} / E_{100}, E_{111} / E_{100}$, and elastic anisotropy parameter $A$ for $\mathrm{L}_{2} \mathrm{Co}_{3}(\mathrm{Al}, \mathrm{Mo}, \mathrm{Nb})$ with the lowest energy structure (str_1) and the intermediate energy structure (str_2) at different temperatures. It can be seen that the elastic properties of $\mathrm{Co}_{3}(\mathrm{Al}, \mathrm{Mo}, \mathrm{Nb})$ with different structures at different temperatures are almost identical. The isentropic elastic constants of $\mathrm{Co}_{3}(\mathrm{Al}, \mathrm{Mo}, \mathrm{Nb})$ decrease monotonically with the increasing of temperature. The decrease in $E_{111}$ is the fastest and the decrease of $E_{100}$ is the slowest with increasing temperature from $300 \mathrm{~K}$ to $1100 \mathrm{~K} . B, G$ and $E$ value of $\mathrm{Co}_{3}(\mathrm{Al}, \mathrm{Mo}, \mathrm{Nb})$ decrease linearly with the rising of temperature. However, the values of $E_{111} / E_{100}, E_{110} / E_{100}$ and $A$ of $\mathrm{Co}_{3}(\mathrm{Al}, \mathrm{Mo}, \mathrm{Nb})$ keep nearly constant with increasing temperature. In 
$\mathrm{Co}_{3}(\mathrm{Al}, \mathrm{Mo}, \mathrm{Nb})$ phase, [100] is the softest direction, which helps to explain the experimentally observed fcc $(\gamma) / \mathrm{L}_{2}\left(\gamma^{\prime}\right)$ two-phase microstructure with $\mathrm{L}_{2}$ precipitates along $<100>$ directions [9, 18]. This structure is expected to lead to the excellent mechanical properties at elevated temperatures.

\subsection{Thermodynamic properties}

In order to verify the methodology in the present work, Fig. 5 shows the predicted thermodynamic properties at finite temperatures compared with experimental results of $\mathrm{Al}$ [44], Co [44], Mo [44], $\mathrm{Nb}$ [44] and $\mathrm{Co}_{3} \mathrm{Mo}$ [45]. A good agreement is observed between calculations and measurements. Fig. 6 illustrates the calculated thermodynamic properties of $\mathrm{Co}_{3}(\mathrm{Al}, \mathrm{Mo}, \mathrm{Nb})$. Fig.6a and Fig.6b show the temperature dependence of entropy and thermal expansion coefficient. In Fig.6c, it is shown that $C_{p}$ is proportional to $T^{3}$ at temperatures near 0 K. Fig. $6 \mathrm{~d}$ shows that the formation enthalpy of $\mathrm{Co}_{3}(\mathrm{Al}, \mathrm{Mo}, \mathrm{Nb})$ keeps nearly constant with respect to temperature and with the value from str_ 1 larger than that of str_2 by $0.4 \mathrm{KJ} / \mathrm{mol}$-atoms. It is notable that the differences in entropy, thermal expansion coefficient and heat capacities of two structures of $\mathrm{Co}_{3}(\mathrm{Al}, \mathrm{Mo}, \mathrm{Nb})$ are negligible. The str_1 is the lowest energy structure, while the str_2 is the intermediate energy structure (near-SQS structure). Although str_1 and str_2 have different atomic configuration, the calculated $E_{0}, V_{0}, B_{0}, B_{0}^{\prime}$ of str_1 are very close to each other, resulting in almost identical the thermodynamic properties.

\section{Conclusions}

Phase stability, electronic structure, elastic, and thermodynamic properties of the $\mathrm{L} 1_{2}$ $\mathrm{Co}_{3}(\mathrm{Al}, \mathrm{Mo}, \mathrm{Nb})$ phase have been obtained from first-principles calculations. A good agreement is found between the calculated results and the experimental data, which validates the present 
methodologies such as the Debye model and the quasistatic approach. Calculated results indicate that $\mathrm{Co}_{3}(\mathrm{Al}, \mathrm{Mo}, \mathrm{Nb})$ is mechanically stable and ductile in nature and possesses covalent-like bonding. Shear and Young's moduli of $\mathrm{Co}_{3}(\mathrm{Al}, \mathrm{Mo}, \mathrm{Nb})$ are larger than those of $\mathrm{Ni}_{3} \mathrm{Al}$ and $\mathrm{Ni}_{3}(\mathrm{Al}, \mathrm{Ta})$ but smaller than those of $\mathrm{Co}_{3}(\mathrm{Al}, \mathrm{W})$. The values of $E_{111} / E_{100}$ and $A$ keep nearly constant with increasing temperature for $\mathrm{Co}_{3}(\mathrm{Al}, \mathrm{Mo}, \mathrm{Nb})$. The temperature has significant effects on heat capacity, entropy and linear thermal expansion coefficient of $\mathrm{Co}_{3}(\mathrm{Al}, \mathrm{Mo}, \mathrm{Nb})$. The present work provides data for the design of novel high-temperature tungsten-free Co-based alloys.

\section{Acknowledgments}

This work is funded by the National Natural Science Foundation of China through grant No. 51201074. Q. Yao acknowledges the support from Jiangsu Government Scholarship for Overseas Studies. The efforts at the Pennsylvania State University were partially supported by the National Science Foundation under grants DMR-1006557 and CMMI-1333999. Firstprinciples calculations were carried out on the LION clusters at the Pennsylvania State University supported by the Materials Simulation Center and the Institute for CyberScience. Calculations were also carried out on the CyberStar cluster funded by the NSF through Grant No. OCI-0821527. 


\section{References}

[1] Feng Q, Nandy T, Tin S, Pollock T. Solidification of high-refractory ruthenium-containing superalloys. Acta Materialia 2003;51:269-84.

[2] Sims CT, Stoloff NS, Hagel WC. superalloys II: high temperature materials for aerospace and industrial power. New York: Wiley; 1987.

[3] Peng ZL, Miura S, Mishima Y. High-Temperature Creep Behavior in $\mathrm{Ni}_{3}(\mathrm{Al}$, Ta) Single Crystals with Different Orientations. Materials Transactions, JIM 1997;38:653-5.

[4] Sato J, Omori T, Oikawa K, Ohnuma I, Kainuma R, Ishida K. Cobalt-base high-temperature alloys. Science 2006;312:90-1.

[5] Suzuki A, Pollock TM. High-temperature strength and deformation of $\gamma / \gamma^{\prime}$ two-phase Co-Al-W-base alloys. Acta Materialia 2008;56:1288-97.

[6] Chinen H, Omori T, Oikawa K, Ohnuma I, Kainuma R, Ishida K. Phase Equilibria and Ternary Intermetallic Compound with $\mathrm{L}_{2}$ Structure in Co-W-Ga System. Journal of phase equilibria and diffusion 2009;30:587-94.

[7] Chinen H, Sato J, Omori T, Oikawa K, Ohnuma I, Kainuma R, et al. New ternary compound $\mathrm{Co}_{3}(\mathrm{Ge}$, W) with $\mathrm{L1}_{2}$ structure. Scripta materialia 2007;56:141-3.

[8] Makineni SK, Nithin B, Chattopadhyay K. Synthesis of a new tungsten-free $\gamma-\gamma^{\prime}$ cobalt-based superalloy by tuning alloying additions. Acta Materialia 2015;85:85-94.

[9] Makineni SK, Nithin B, Chattopadhyay K. A new tungsten-free $\gamma-\gamma^{\prime}$ Co-Al-Mo-Nb-based superalloy. Scripta Materialia 2015;98:36-9.

[10] Shang SL, Kim D, Zacherl C, Wang Y, Du Y, Liu ZK. Effects of alloying elements and temperature on the elastic properties of dilute Ni-base superalloys from first-principles calculations. Journal of Applied Physics 2012;112:053515.

[11] Baghmar D, Gaur N, Gupta D. Structural and elastic properties of copper iodide. Physica B: Condensed Matter 2010;405:133-9. 
[12] Yao Q, Sun J, Zhang Y, Jiang B. First-principles studies of ternary site occupancy in the C15 $\mathrm{NbCr}_{2}$ Laves phase. Acta materialia 2006;54:3585-91.

[13] Joshi SR, Vamsi KV, Karthikeyan S. First principles study of structural stability and site preference in $\mathrm{Co}_{3}(\mathrm{~W}, \mathrm{X})$. Eurosuperalloys 2014 - 2nd European Symposium on Superalloys and Their Applications $2014 ; 14$.

[14] Xu WW, Han JJ, Wang ZW, Wang CP, Wen YH, Liu XJ, et al. Thermodynamic, structural and elastic properties of $\mathrm{Co}_{3} \mathrm{X}(\mathrm{X}=\mathrm{Ti}, \mathrm{Ta}, \mathrm{W}, \mathrm{V}, \mathrm{Al})$ compounds from first-principles calculations. Intermetallics 2013;32:303-11.

[15] Yao Q, Zhu YH, Wang Y. Structural stability and elastic properties of $\mathrm{L1}_{2} \mathrm{Co}_{3}(\mathrm{Ga}, \mathrm{W})$ precipitate from first-principle calculations. Physica B-Condensed Matter 2011;406:1542-5.

[16] Yao Q, Wang Y, Zhu YH. Elastic properties and electronic structures of $\mathrm{L}_{2} \mathrm{Co}_{3}(\mathrm{Ge}, \mathrm{W})$. Physica BCondensed Matter 2010;405:2753-6.

[17] Chen M, Wang CY. First-principles investigation of the site preference and alloying effect of Mo, Ta and platinum group metals in $\gamma^{\prime}-\mathrm{Co}_{3}(\mathrm{Al}, \mathrm{W})$. Scripta Materialia 2009;60:659-62.

[18] Jiang C. First-principles study of $\mathrm{Co}_{3}(\mathrm{Al}, \mathrm{W})$ alloys using special quasi-random structures. Scripta Materialia 2008;59:1075-8.

[19] Tanaka K, Ohashi T, Kishida K, Inui H. Single-crystal elastic constants of $\mathrm{Co}_{3}(\mathrm{Al}, \mathrm{W})$ with the $\mathrm{L1}_{2}$ structure. Applied Physics Letters 2007;91.

[20] Yao Q, Xing H, Sun J. Structural stability and elastic property of the $\mathrm{L}_{2}$ ordered $\mathrm{Co}_{3}(\mathrm{Al}, \mathrm{W})$ precipitate. Applied Physics Letters 2006;89.

[21] Makineni S, Samanta A, Rojhirunsakool T, Alam T, Nithin B, Singh A, et al. A new class of high strength high temperature Cobalt based $\gamma-\gamma^{\prime}$ Co-Mo-Al alloys stabilized with Ta addition. Acta Materialia 2015;97:29-40.

[22] JENSRUD O. Hardening mechanisms and ductility of an Al-3.0 wt.\% Li alloy. Aluminium-lithium alloys III. The Institute of Metals; 1986, pp. 411-9. 
[23] Van de Walle A, Asta M, Ceder G. The alloy theoretic automated toolkit: A user guide. Calphad 2002;26:539-53.

[24] Shang SL, Wang Y, Wang WY, Fang H, Liu ZK. Low energy structures of lithium-ion battery materials $\mathrm{Li}\left(\mathrm{Mn}_{\mathrm{x}} \mathrm{Ni}_{\mathrm{x}} \mathrm{Co}_{1-}{ }_{\mathrm{x}}\right) \mathrm{O}_{2}$ revealed by first-principles calculations. Applied Physics Letters 2013;103:053903.

[25] Zunger A, Wei S, Ferreira LG, Bernard JE. Special quasirandom structures. Physical Review Letters 1990;65:353-6.

[26] Kresse G, Joubert D. From ultrasoft pseudopotentials to the projector augmented-wave method. Physical Review B 1999;59:1758.

[27] Kresse G, Furthmüller J. Software VASP, vienna (1999). Phys Rev B 1996;54:169.

[28] Perdew JP, Burke K, Ernzerhof M. Generalized gradient approximation made simple. Physical review letters 1996;77:3865.

[29] Blöchl PE, Jepsen O, Andersen OK. Improved tetrahedron method for Brillouin-zone integrations. Physical Review B 1994;49:16223.

[30] Shang SL, Wang Y, Liu ZK. First-principles elastic constants of $\alpha$-and $\theta-\mathrm{Al}_{2} \mathrm{O}_{3}$. Applied Physics Letters 2007;90:101909.

[31] Wang Y, Wang J, Zhang H, Manga V, Shang SL, Chen L, et al. A first-principles approach to finite temperature elastic constants. Journal of Physics: Condensed Matter 2010;22:225404.

[32] Anderson OL. A simplified method for calculating the Debye temperature from elastic constants. Journal of Physics and Chemistry of Solids 1963;24:909-17.

[33] Gutkin MY, Ishizaki T, Kuramoto S, Ovid'ko IA. Nanodisturbances in deformed gum metal. Acta materialia 2006;54:2489-99.

[34] Moruzzi V, Janak J, Schwarz K. Calculated thermal properties of metals. Physical Review B 1988;37:790. 
[35] Shang SL, Wang Y, Kim D, Liu ZK. First-principles thermodynamics from phonon and Debye model: Application to $\mathrm{Ni}$ and $\mathrm{Ni}_{3} \mathrm{Al}$. Computational Materials Science 2010;47:1040-8.

[36] Xu WW, Han JJ, Wang Y, Wang CP, Liu XJ, Liu ZK. First-principles investigation of electronic, mechanical and thermodynamic properties of $\mathrm{L}_{2}$ ordered $\mathrm{Co}_{3}(\mathrm{M}, \mathrm{W})(\mathrm{M}=\mathrm{Al}, \mathrm{Ge}, \mathrm{Ga})$ phases. Acta Materialia 2013;61:5437-48.

[37] Xu JH, Oguchi T, Freeman A. Solid-solution strengthening: Substitution of $\mathrm{V}$ in $\mathrm{Ni}_{3} \mathrm{Al}$ and structural stability of $\mathrm{Ni}_{3}(\mathrm{Al}, \mathrm{V})$. Physical Review B 1987;36:4186.

[38] Wang YJ, Wang CY. A comparison of the ideal strength between $\mathrm{L1}_{2} \mathrm{Co}_{3}(\mathrm{Al}, \mathrm{W})$ and $\mathrm{Ni}_{3} \mathrm{Al}$ under tension and shear from first-principles calculations. Applied Physics Letters 2009;94:261909.

[39] Kayser F, Stassis C. The elastic constants of $\mathrm{Ni}_{3} \mathrm{Al}$ at 0 and $23.5 \mathrm{C}$. Physica status solidi (a) $1981 ; 64: 335-42$.

[40] Born M, Huang K. Dynamical Theory of Crystal Lattices. Clarendon press, oxford; 1954.

[41] Pugh S. The London, Edinburgh, and Dublin Philosophical Magazine and Journal of Science: Series 7. Philos Mag 1954;45:823.

[42] Pettifor D. Theoretical predictions of structure and related properties of intermetallics. Materials science and technology 1992;8:345-9.

[43] Prikhodko S, Yang H, Ardell A, Carnes J, Isaak D. Temperature and composition dependence of the elastic constants of $\mathrm{Ni}_{3} \mathrm{Al}$. Metallurgical and Materials Transactions A 1999;30:2403-8.

[44] Chase M. NIST_JANAF Thermochemical Tables (Journal of Physical and Chemical Reference Data Monograph No. 9). American Institute of Physics, 1998.

[45] Davydov A, Kattner U. Thermodynamic assessment of the Co-Mo system. Journal of phase equilibria 1999;20:5-16. 
Figures and Figure Captions:

Fig. 1. Calculated total energies for all the seventeen supercell structures of $\mathrm{L}_{2} \mathrm{Co}_{3}(\mathrm{Al}, \mathrm{Mo}, \mathrm{Nb})$.

The structures with the lowest energy (str_1) and the intermediate energy (str_2) are shown.

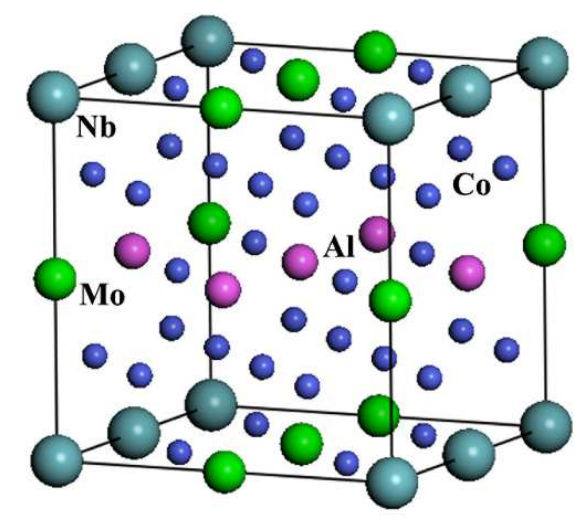

Lowest energy (str_1)

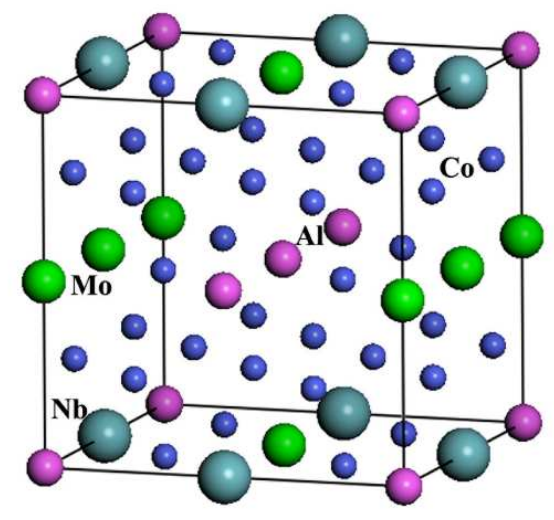

Intermediate energy (str_2)

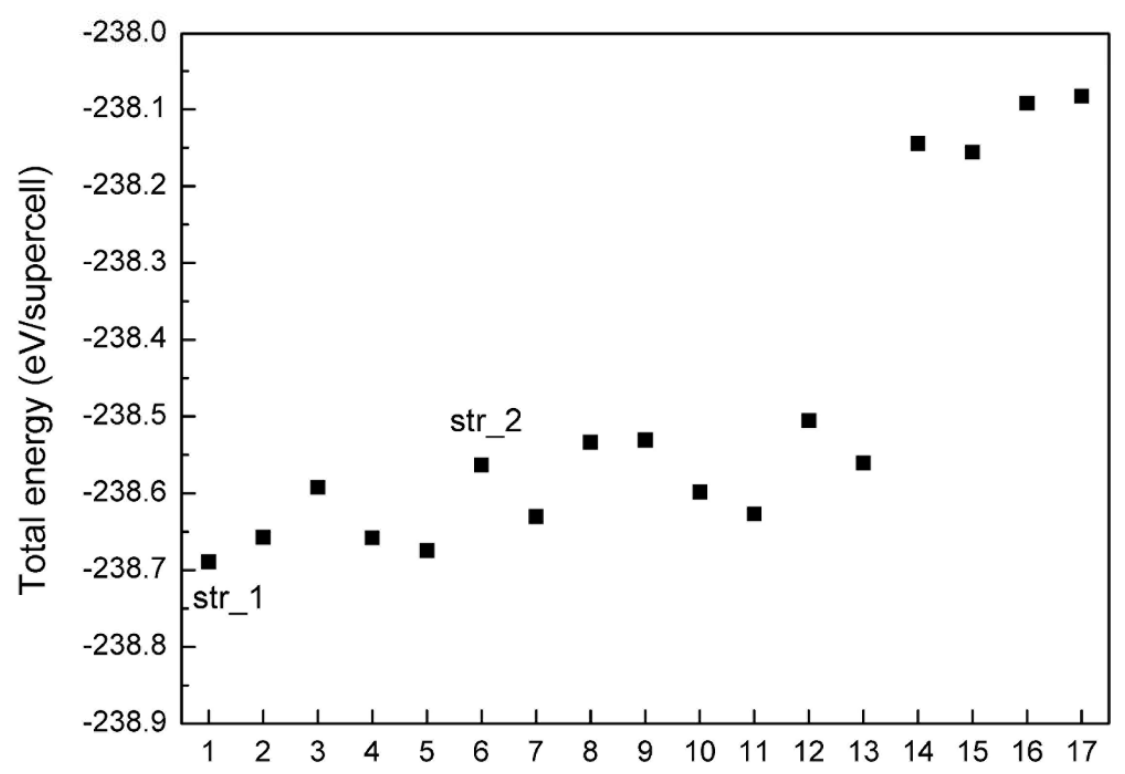


Fig. 2. Calculated total electronic density of states (TDOS) and partial electronic density of states (PDOS) for the $\mathrm{L}_{2} \mathrm{Co}_{3}(\mathrm{Al}, \mathrm{Mo}, \mathrm{Nb})$ based on str_1. The Fermi level is shifted zero energy.

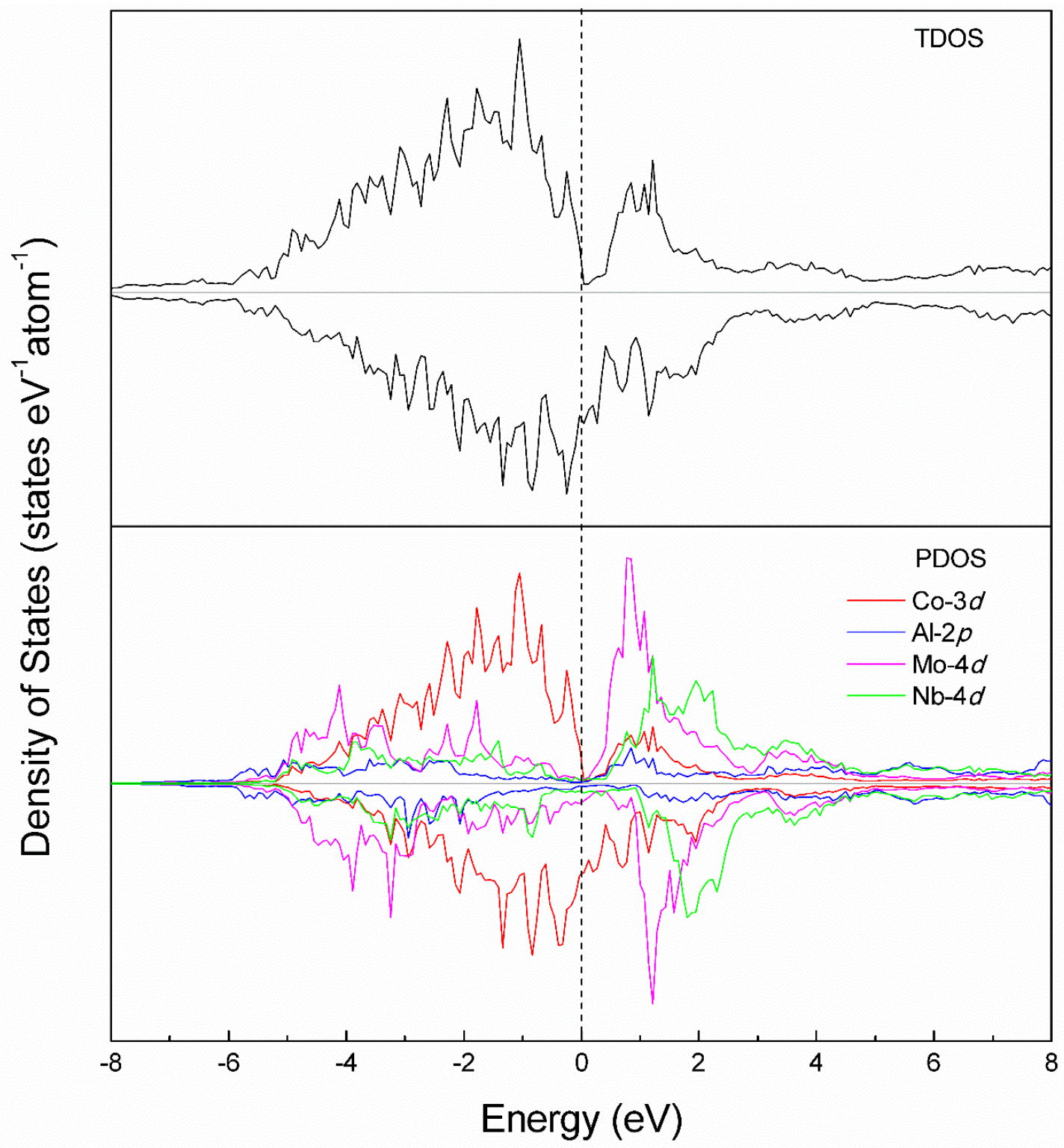


Fig. 3. Calculated isothermal elastic constants $\left(C_{11}^{T}: \square, C_{12}^{T}: \triangle\right.$, and $\left.C_{44}^{T}: 乏\right)$ and isentropic elastic constants $\left(C_{11}^{S}: \bigcirc, C_{12}^{S}: \nabla\right.$, and $\left.C_{44}^{S}: \mathcal{\zeta}\right)$ for $\mathrm{Ni}_{3} \mathrm{Al}$ at $300,600,900$, and $1100 \mathrm{~K}$ in comparison with experimental data by Prikhodko et al [43] $\left(C_{11}^{S}: \mathbf{O}, C_{12}^{S}: \boldsymbol{\nabla}\right.$, and $\left.C_{44}^{S}: \star\right)$.

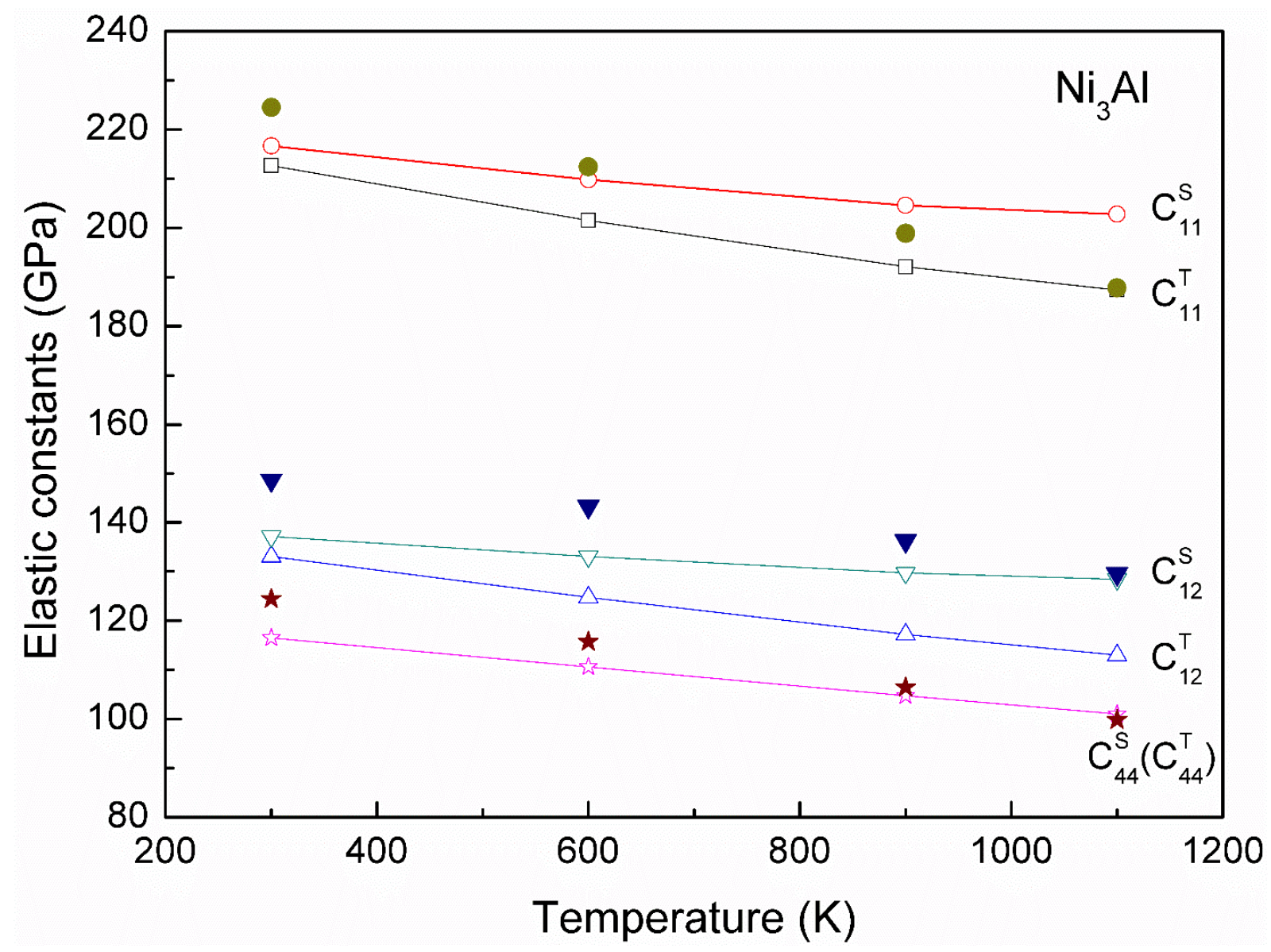


Fig. 4. Calculated isentropic elastic constant $C_{i j}^{S}$, elastic properties (i.e., $B, G$ and $E$ ), Young's modulus in the [hkl] direction $E_{\mathrm{hkl}}, E_{110} / E_{100}, E_{111} / E_{100}$, and elastic anisotropy parameter $A$ of $\mathrm{L}_{2}$ $\mathrm{Co}_{3}(\mathrm{Al}, \mathrm{Mo}, \mathrm{Nb})$ with the lowest energy structure (str_1) and the intermediate energy structure (str_2) at different temperatures, respectively.
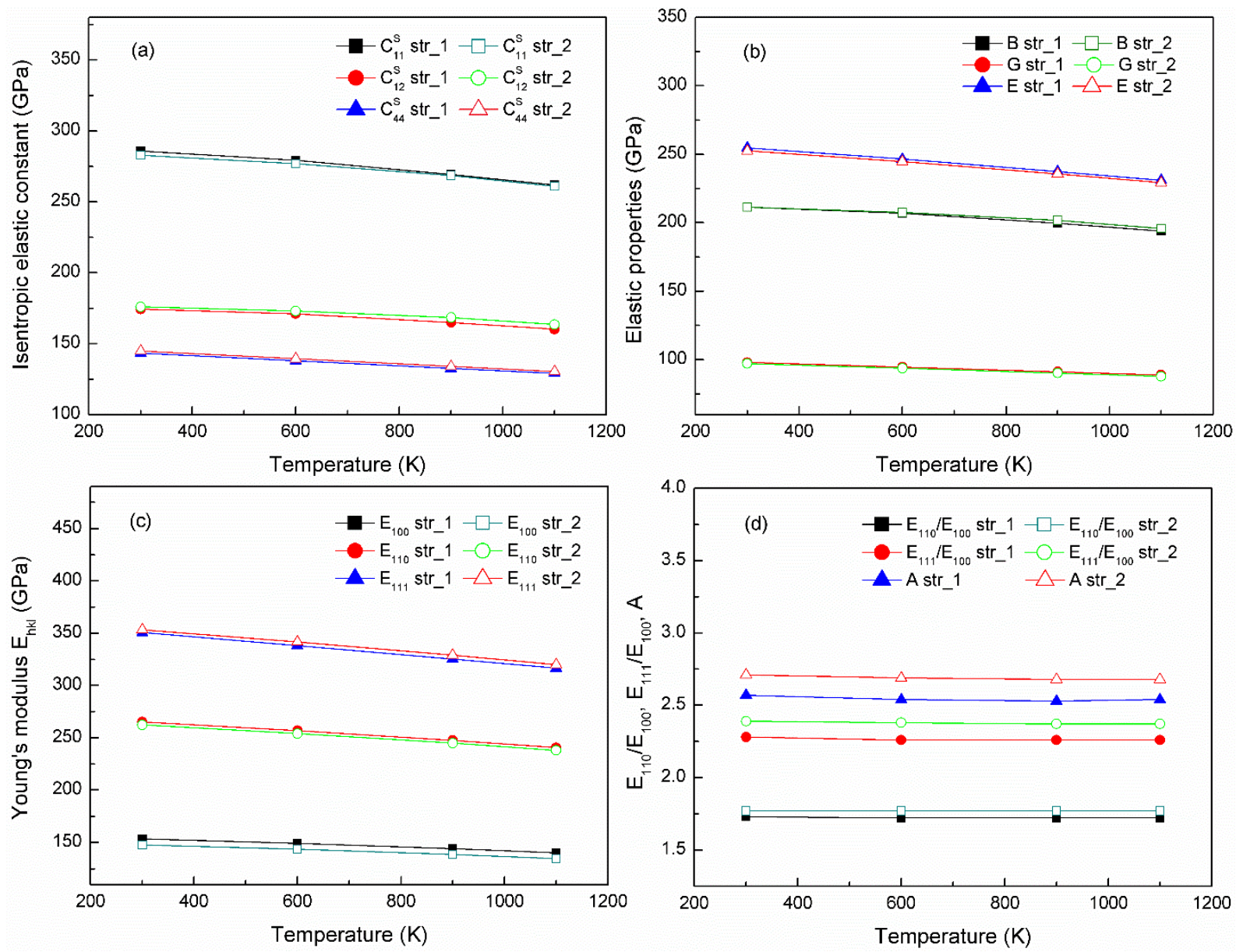
Fig. 5. Thermodynamic properties as a function of temperature for fcc Al, hcp Co, bcc Mo, bcc $\mathrm{Nb}$ and $\mathrm{Co}_{3} \mathrm{Mo}$ : (a) entropy $(\mathrm{S})$; (b) isobaric heat capacity $\left(\mathrm{C}_{\mathrm{p}}\right)$; (c) enthalpy of formation $(\Delta \mathrm{H})$; (d) entropy of formation $(\Delta S)$. The recommended values (open symbols) are shown for Al [44], Co [44], Mo [44], $\mathrm{Nb}$ [44] and $\mathrm{Co}_{3} \mathrm{Mo}$ [45].
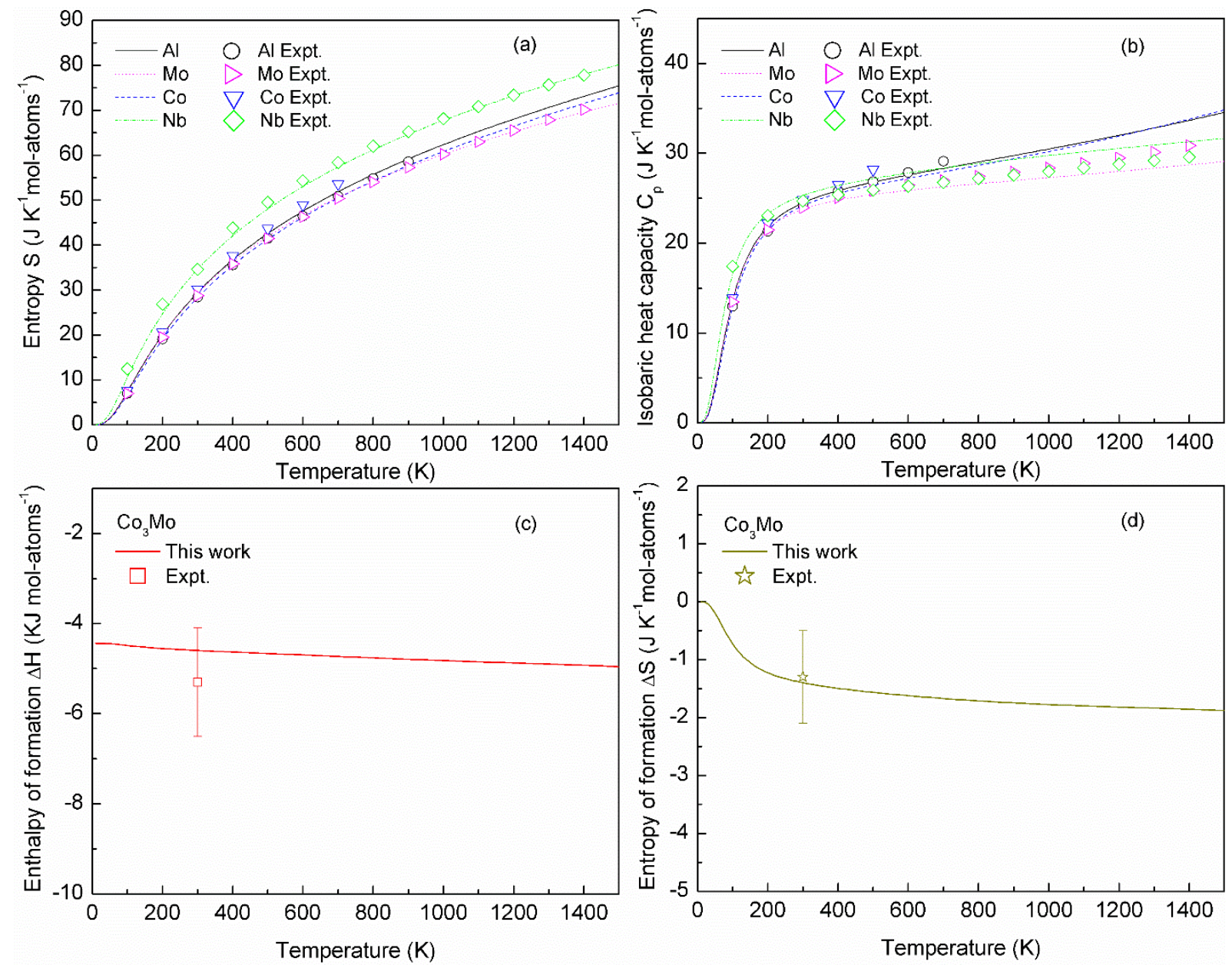
Fig. 6. Temperature-dependent thermodynamic function of $\mathrm{L}_{2} \mathrm{Co}_{3}(\mathrm{Al}, \mathrm{Mo}, \mathrm{Nb})$ with the lowest energy structure (str_1: red dashed line) and the intermediate energy structure (str_2: black solid line): (a) entropy (S); (b) linear thermal expansion coefficient; (c)isobaric heat capacity $\left(\mathrm{C}_{\mathrm{p}}\right)$; (d) enthalpy of formation $(\Delta \mathrm{H})$.
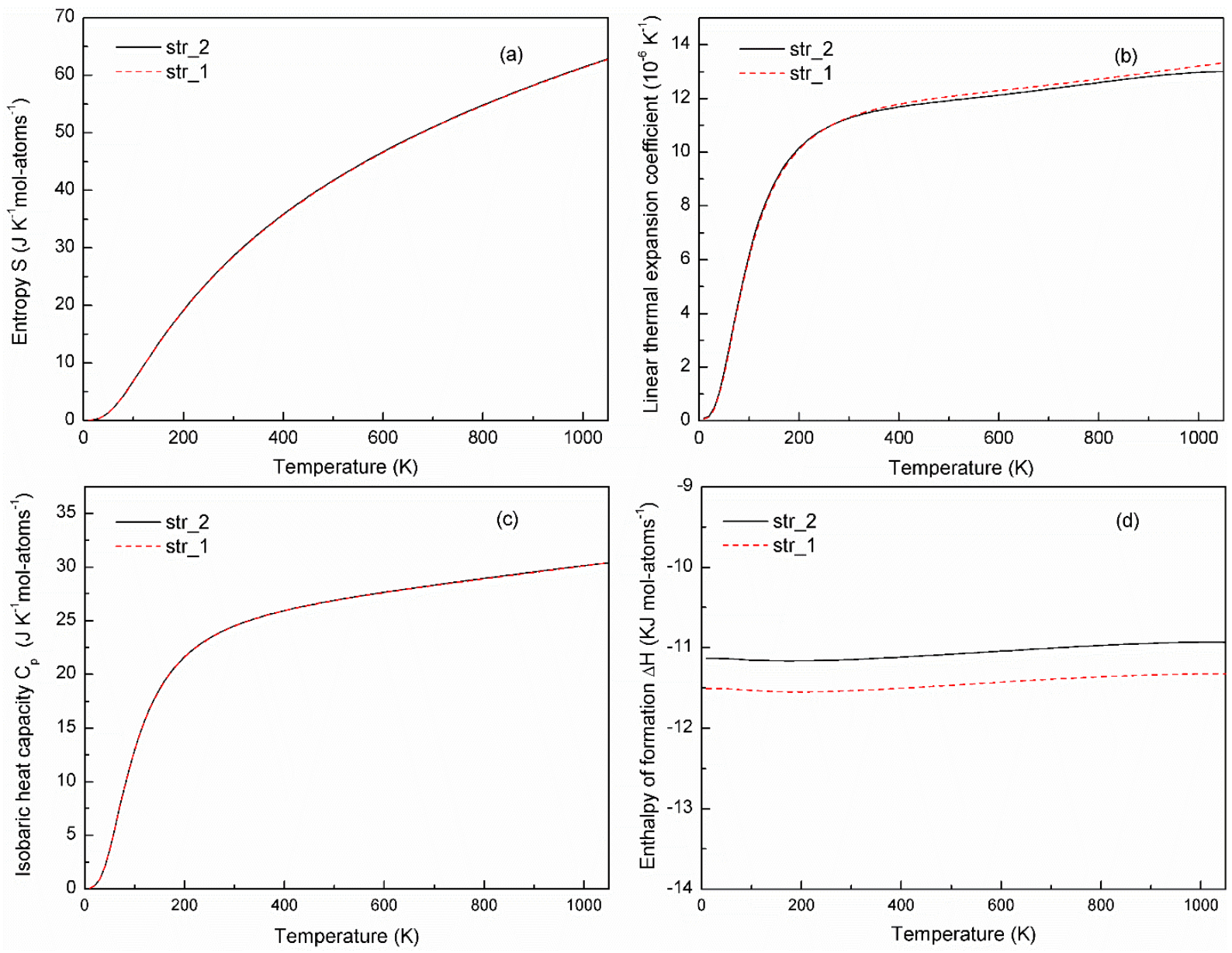
Table 1

Calculated equilibrium lattice constant a $(\mathrm{nm})$ and enthalpy of formation $\Delta \mathrm{H}(\mathrm{kJ} / \mathrm{mol}$-atoms) for $\mathrm{Co}_{3}(\mathrm{Al}, \mathrm{Mo}, \mathrm{Nb})$ and $\mathrm{Co}_{3}(\mathrm{Al}, \mathrm{W})$.

\begin{tabular}{cccc}
\hline & Method & $\mathrm{a}$ & $\Delta \mathrm{H}$ \\
\hline $\mathrm{Co}_{3}(\mathrm{Al}, \mathrm{Mo}, \mathrm{Nb})$-str_1 & Calc. $^{\mathrm{a}}$ & 0.3599 & -11.63 \\
$\mathrm{Co}_{3}(\mathrm{Al}, \mathrm{Mo}, \mathrm{Nb})-$ str_2 $^{\mathrm{a}}$ & Calc. $^{\mathrm{a}}$ & 0.3599 & -11.25 \\
$\mathrm{Co}_{3}(\mathrm{Al}, \mathrm{W})$ & Calc. $^{\mathrm{a}}$ & 0.3567 & -12.16 \\
& Calc. $^{\mathrm{b}}$ & 0.3566 & -14.96 \\
& Expt. $^{\mathrm{c}}$ & 0.3599 & - \\
\hline
\end{tabular}

\footnotetext{
${ }^{\mathrm{a}}$ This work.

${ }^{\mathrm{b}} \operatorname{Ref}[36]$.

${ }^{\mathrm{c}} \operatorname{Ref}[4]$.
} 
Table 2

Calculated and experimental elastic properties, including $C_{\mathrm{ij}}, B, G$ and $E, B / G$, Cauchy pressure $C_{12}-C_{44}$, Young's modulus along the [hkl] direction $E_{\mathrm{hkl}}, \mathrm{E}_{110} / \mathrm{E}_{100}, \mathrm{E}_{111} / \mathrm{E}_{100}$ and elastic anisotropy parameter $A$ for $\mathrm{Co}_{3}(\mathrm{Al}, \mathrm{Mo}, \mathrm{Nb}), \mathrm{Ni}_{3} \mathrm{Al}$, and $\mathrm{Co}_{3}(\mathrm{Al}, \mathrm{W})$ at $0 \mathrm{~K}$. The unit of elastic properties is $\mathrm{GPa}$, and the properties of $\mathrm{Ni}_{3}(\mathrm{Al}, \mathrm{Ta})$ are listed for comparison.

\begin{tabular}{|c|c|c|c|c|c|c|c|c|c|c|c|c|c|c|c|}
\hline & Method & $C_{11}$ & $C_{12}$ & $C_{44}$ & $B$ & $G$ & $E$ & $B / G$ & $C_{12}-C_{44}$ & $E_{100}$ & $E_{110}$ & $E_{111}$ & $E_{110} / E_{100}$ & $E_{111} / E_{100}$ & $A$ \\
\hline $\begin{array}{l}\mathrm{Co}_{3}(\mathrm{Al}, \mathrm{Mo} \\
\mathrm{Nb})-\mathrm{str} \_1\end{array}$ & Calc. $^{\mathrm{a}}$ & 290.7 & 176.6 & 149.6 & 214.6 & 101.7 & 263.4 & 2.11 & 27.0 & 157.2 & 274.0 & 364.2 & 1.74 & 2.32 & 2.62 \\
\hline $\begin{array}{l}\mathrm{Co}_{3}(\mathrm{Al}, \mathrm{Mo}, \\
\mathrm{Nb})-\mathrm{str} 22\end{array}$ & Calc. $^{a}$ & 286.7 & 177.1 & 150.7 & 213.6 & 100.5 & 260.6 & 2.13 & 26.4 & 151.4 & 270.3 & 366.1 & 1.78 & 2.42 & 2.75 \\
\hline \multirow[t]{2}{*}{$\mathrm{Ni}_{3} \mathrm{Al}$} & Calc. ${ }^{\mathrm{a}}$ & 226.9 & 143.5 & 123.1 & 171.3 & 79.8 & 207.3 & 2.15 & 20.4 & 115.7 & 213.8 & 297.9 & 1.85 & 2.57 & 2.95 \\
\hline & Expt. $^{b}$ & 223 & 148 & 125 & 173 & 77 & 201 & 2.25 & 23 & 104.9 & 205.6 & 302.2 & 1.96 & 2.88 & 3.33 \\
\hline \multirow[t]{3}{*}{$\mathrm{Co}_{3}(\mathrm{Al}, \mathrm{W})$} & Calc. $^{a}$ & 304.1 & 184.6 & 175.9 & 224.4 & 114.2 & 292.9 & 1.96 & 8.7 & 164.7 & 302.1 & 418.4 & 1.83 & 2.54 & 2.94 \\
\hline & Calc. $^{\mathrm{c}}$ & 301 & 169 & 172 & 213 & 117 & 297 & 1.82 & -3 & 179.5 & 308.9 & 406.6 & 1.72 & 2.27 & 2.61 \\
\hline & Expt. $^{\mathrm{d}}$ & 271 & 172 & 162 & 205 & 101 & 260 & 2.03 & 10 & 137.4 & 265.3 & 384.7 & 1.93 & 2.80 & 3.27 \\
\hline $\mathrm{Ni}_{3}(\mathrm{Al}, \mathrm{Ta})$ & Expt. $^{\mathrm{d}}$ & 238 & 154 & 130 & 182 & 82.8 & 216 & 2.20 & 24 & 117.0 & 221.4 & 315.0 & 1.89 & 2.69 & 3.09 \\
\hline
\end{tabular}

${ }^{\mathrm{a}}$ This work.

${ }^{\mathrm{b}} \operatorname{Ref}[39]$.

${ }^{\mathrm{c}} \operatorname{Ref}[38]$.

${ }^{\mathrm{d}} \operatorname{Ref}[19]$. 